\title{
MEMÓRIAS DA PRIMEIRA GUERRA MUNDIAL EM ERICH MARIA REMARQUE E ERNEST HEMINGWAY
}

\author{
Diana Navas \\ Doutora pela - PUC/SP \\ diana.navas@hotmail.com \\ Evandro Fantoni Rodrigues Alves \\ Mestrando em Literatura e Crítica Literária - PUC/SP \\ evandro.fantoni.ra@gmail.com
}

\section{RESUMO}

$O$ século $X X$ foi testemunha de um significativo número de eventos altamente transformadores da sociedade e da cultura como um todo, dentre os quais podemos destacar a ocorrência da Primeira Guerra Mundial, entre os anos de 1914 e 1918. Entre os sobreviventes da Grande Guerra que procuraram traduzir em textos suas memórias dos anos de conflito, encontramos Ernest Hemingway e Erich Maria Remarque, que em seus romances Adeus às armas, e Nada de novo no front, respectivamente, trouxeram para a literatura aspectos de suas próprias experiências no front. É baseando-se nas obras desses dois grandes autores que o presente artigo objetiva apresentar alguns aspectos da memória construída acerca da Primeira Guerra Mundial - na medida em que a ideia corrente no período da glória da guerra foi-se desmanchando diante da cruel realidade das trincheiras-e compreender como essa realidade aparece literariamente representada por estes dois autores.

Palavras-chave: Memórias, Ernest Hemingway, Adeus às armas, Erich Maria Remarque, Nada de novo no front.

ABSTRACT
The 20th century was witness to an uncountable number of highly revolutionary events for society and culture, and among them we can focus on the occurrence of World War I, between the years of 1914 and 1918. Among the survivors who wanted to put into texts their memories from the conflict, we can find Ernest Hemingway and Erich Maria Remarque, who brought to literature aspects of their own experiences on the front in their books A Farewell to arms, and Im westen nichts neues, respectively. Based on the works of these two great writers, the present text aims to present some aspects of the built memory from World War I - while the common idea of a glorious war was vanishing in front of the cruel reality of the trenches - and to understand how this reality appears literarily represented by these writers.

Keywords: Memories, Ernest Hemingway, A Farewell to the arms, Erich Maria Remarque, In westen nichts neues. 


\section{GUERRA E MEMÓRIA: BREVES CONSIDERAÇÕES}

A Primeira Guerra Mundial, também denominada muitas vezes de A Grande Guerra, ou mesmo, segundo seus defensores na época de sua eclosão, "a guerra para acabar com todas as guerras", pode ser considerada um dos mais emblemáticos - o mais corretamente seria dizer traumáticos - acontecimentos do século $\mathrm{XX}$, e talvez até de toda a História humana. Não seria nenhum tipo de exagero afirmar que os acontecimentos ocorridos entre os anos de 1914 e 1918 podem ser considerados altamente transformadores da sociedade humana e, consequentemente, da cultura vigente até então.

As consequências da Primeira Guerra Mundial podem ser medidas nos mais diferentes aspectos sociais e culturais, e revolucionaram desde aspectos menores da cultura humana, como um todo, e europeia, em especial - como a simples percepção do que seria um período de paz, tido como praticamente impossível após 1914, mesmo nos momentos em que não ocorriam conflitos bélicos mais diretos, como entre os anos de 1918 e 1939, de acordo com o historiador inglês Eric Hobsbawn (1995) - até questionamentos mais profundos da própria ordem política e social - como a legitimidade governamental das monarquias, cujo ápice foi o ato revolucionário russo, em 1917, contra os imperadores que levaram a população ao conflito bélico.

A mais evidente, e talvez mais importante, consequência trazida pela Primeira Guerra Mundial pode ser encontrada, contudo, na própria ideia de percepção e memória da guerra em si. Ou seja, os traumas que a Primeira Guerra Mundial causaram aos seus participantes foram tão intensos e profundos, e as memórias deixadas em seus combatentes tão 
retumbantes e indeléveis que, mesmo no início do conflito, tornou-se evidente que suas consequências seriam devastadoras, e que jamais, depois do conflito, homens de consciência escreveriam textos ou pronunciariam discursos glorificando a guerra como algo positivo. Ainda de acordo Hobsbawn (1995), o secretário de relações exteriores da Grã-Bretanha, Edward Gray, teria declarado que todas as luzes sobre a Europa se apagaram quando seu país e a Alemanha partiram para o confronto.

O mesmo historiador assegura-nos que a maioria esmagadora dos soldados que partiram para o front e sobreviveram a ele voltaram para seus lares, depois de encerrado o conflito, dotados de um profundo sentimento anti-bélico por terem encontrado nas trincheiras não as glórias que lhes eram prometidas, mas, sim, um inferno verdadeiro, de proporções dantescas, e que Hobsbawn assim descreve em A Era dos Extremos:

Milhões de homens ficavam uns diante dos outros nos parapeitos de trincheiras barricadas com sacos de areia, sob as quais viviam como - e com ratos e piolhos. De vez em quando seus generais procuravam romper o impasse. Dias e mesmo semanas de incessante bombardeio de artilharia - que um escritor alemão chamou depois de "furacões de aço" (Ernst Jünger, 1921) - "amaciavam" o inimigo e o mandavam para baixo da terra, até que no momento certo levas de homens saíam por cima do parapeito, geralmente protegido por rolos e teias de arame farpado, para a "terra de ninguém", um caos de crateras de granadas inundadas de água, tocos de árvores calcinadas, lama e cadáveres abandonados, e avançavam sobre as metralhadoras, que os ceifavam, como eles sabiam que aconteceria. A tentativa alemã de romper a barreira em Verdun, em 1916 (fevereiro-julho), foi uma batalha de 2 milhões de homens, com 1 milhão de baixas (HOBSBAWN, 1995, p.33).

Ao ler a descrição de Eric Hobsbawn acerca de algumas das condições de vida e combate dos soldados nas trincheiras da Primeira Guerra Mundial, podemos imaginar os tipos de memórias que os sobreviventes trouxeram para casa depois de finalizado o 
combate, bem como as experiências transformadoras que haviam tido nos campos de batalha. Giorgio Agamben nos traz algumas palavras que podem ser úteis na compreensão da questão da memória/experiência dos soldados nos campos de batalha:

Benjamin, que já em 1933 havia diagnosticado com precisão essa "pobreza de experiência" da época moderna, indicava suas causas na catástrofe da guerra mundial, de cujos campos de batalhas “a gente voltava emudecida... não mais rica, porém mais pobre de experiências partilháveis... [...] as experiências estratégicas da guerra de posição, as experiências econômicas da inflação, as experiências corpóreas na fome, as experiências morais no despotismo" (AGAMBEN, 2005, p.21).

Partindo das palavras de Agamben, parece-nos importante questionar os motivos pelos quais - mesmo diante de experiências perdidas e traumáticas, impossíveis de partilhar - constata-se a significativa presença da memória, e mais especificamente da reprodução escrita da memória, seja na forma de crônicas, seja na forma de narrativas romanescas - que é o caso que mais nos interessa no presente artigo - em termos culturais, não mais individuais de um sobrevivente da catástrofe militar das trincheiras, mas como um testemunho complexo de um episódio que, individualmente, se desejaria esquecer.

Acreditamos que, nesse ponto, se faz necessária uma consideração acerca da questão da memória e de sua compreensão em termos individuais e em termos coletivos, ou culturais.

Compreendemos que a questão da memória segue dois caminhos opostos - embora não nulificantes - quando é abordada por uma perspectiva individual e quando é abordada por uma perspectiva mais social ou cultural. O fenômeno da memória, quando encarado individualmente sob a ótica da experiência, tende para o desaparecimento individual da experiência traumática e impartilhável através do processo de esquecimento por parte do 
indivíduo, ainda que a própria força da experiência traumática torne impossível esse processo de esquecimento, mesmo que desejável por aquele que viveu a experiência, ou seja, um indivíduo que possua experiências impartilháveis e traumáticas acumuladas na forma da memória tenderá a desejar o desaparecimento dessas memórias/experiências, pela própria dor e isolamento que elas causam. O paradoxo desse ponto é justamente a intensidade da dor e do isolamento que impedem que o desejo de desaparecimento dessa memória individual possa se concretizar.

Por outro lado, quando abordamos a memória de forma coletiva, ou mais precisamente de forma social e cultural, o movimento é o oposto, no sentido de que os diferentes grupos afetados pelas experiências traumáticas e impartilháveis, coletivamente se coloquem como defensores dessa memória, mesmo que individualmente tais experiências Ihes causem sofrimento e sensação de isolamento. Esse movimento se dá devido ao fato de que, se caladas as memórias de episódios sociais e culturalmente traumáticos, não haverá nenhuma força capaz de impedir que os mesmos eventos se repitam. Nesse sentido é que, culturalmente, as memórias e experiências, por mais intensas e traumáticas que sejam, e especificamente por serem intensas e traumáticas, assumem uma importância capital, pois o rememorar da experiência coletiva traumática é a arma da História e da Cultura para combater a recorrência dessas mesmas experiências por outros indivíduos.

Esse uso cultural - e mesmo político e social - da memória contra a política de esquecimento fica evidente, inclusive, na fala de Hitler a respeito do Holocausto, o qual argumentou, em defesa de seu projeto de extermínio do povo judeu, que em poucos anos ninguém se lembraria dos campos de concentração, da mesma maneira que ninguém mais 
falava, à época da Segunda Guerra Mundial, do massacre perpetrado pelos turcos contra os armênios em 1915, durante a ocorrência da Primeira Guerra, e negado até hoje pela autoridades turcas, conforme assegura-nos Jeanne Marie Gagnebin:

Querendo aniquilar um povo inteiro, a "solução final" pretendia também destruir toda uma face da história e da memória. Essa capacidade de destruição da memória cobre uma dimensão política e ética a respeito da qual Hitler estava perfeitamente consciente. [...] "Eu dei ordem às unidades especiais da SS de se apoderarem do fronte polonês e de matarem sem piedade homens, mulheres e crianças. Quem ainda fala dos extermínios dos armênios, hoje?", declara ele em 21 de agosto de 1939 (GAGNEBIN, 2014, p.47).

Hobsbawn (1995) também nos fornece argumentos a esse respeito ao afirmar que, percebendo a iminência da derrota, os oficiais nazistas explodiram câmaras de gás e toda sorte de documentação possível a respeito do Holocausto, com o objetivo de poder negar, assim, a sua existência.

Ainda a respeito do conceito de memória e de seus usos, é importante destacar que a memória não deve ser confundida ou assumida, necessária e incontestavelmente, como um sinônimo da verdade, uma vez que ela, individual ou coletiva, pode ser construída e, portanto, está necessariamente sujeita aos efeitos da mente humana que, muitas vezes, não nos oferece os fatos exatamente como ocorreram, mas as percepções individuais desses fatos que nossos cérebros registraram como elementos mais significativos. Walter Benjamin, em seu trabalho Sobre o conceito de História, apresenta-nos uma definição bastante interessante de passado, a qual, no caso do presente artigo, pode também ser aplicável à ideia de memória. Assim afirma o teórico alemão:

A verdadeira imagem do passado passa voando. O passado só se deixa capturar como imagem que relampeja irreversivelmente no momento de sua conhecibilidade. [...] Articular 
historicamente o passado não significa conhecê-lo "tal como ele de fato foi". Significa apropriar-se de uma recordação, como ela relampeja no momento de um perigo (BENJAMIN, 2016, p.243).

Para concluir essa primeira discussão acerca da concepção de memória e de sua importância cultural, em especial nos dias de hoje, em que muito se discutem valores e surgem movimentos revisionistas de eventos históricos, recorremos a uma definição simples de Jeanne Marie Gagnebin, que contém, em suas poucas palavras, o cerne dos conceitos que aqui apresentamos e que servirão de norte para a análise da presença memorialística da Primeira Guerra Mundial que encontramos em Hemingway e Remarque:

[...]O que ganhamos nesse percurso? Paradoxalmente, a consciência da fragilidade essencial do rastro, da fragilidade essencial da memória e da escrita. E, ao mesmo tempo, uma definição certamente polêmica, paradoxal e, ainda, constrangedora da tarefa do historiador: é necessário lutar contra o esquecimento e a denegação, lutar, em suma, contra a mentira, mas sem cair em uma definição dogmática de verdade (GAGNEBIN, 2014, p.44).

Tendo estabelecido esses pressupostos a respeito das questões relacionadas à memória e à experiência, podemos partir agora para uma análise mais aprofundada das questões relativas às memórias da Primeira Guerra Mundial presentes de forma literária nos romances de Erich Maria Remarque e Ernest Hemingway.

\section{AS MEMÓRIAS DA GUERRA EM REMARQUE E HEMINGWAY}

O primeiro ponto que merece destaque nesse particular e que é a base de sustentação da ideia de memória da Primeira Guerra Mundial representada literariamente, é o fato de os dois autores terem participado como combatentes durante o conflito.

A narrativa de Adeus às armas, de Ernest Hemingway, publicada em 1929, conta a história de Henry Frederic, cidadão norte-americano que se alistou como voluntário no 
exército italiano e atuou no front como motorista de ambulância, sob a patente de tenente. A personagem sofre um grave ferimento na perna, em decorrência do obus de um morteiro, que o tira temporariamente da frente de combate, e o leva a conhecer Catherine, enfermeira inglesa que cuida de seus ferimentos e com quem estabelece um relacionamento. Ainda que seja bastante arriscado falar em termos como autoficção - uma vez que não nos aprofundaremos, aqui, nesta discussão - é bastante evidente a proximidade da narrativa com a biografia do autor permitindo-nos inferir, com certo grau de certeza, que a inspiração para a composição do texto ficcional vem das memórias do próprio autor e do que presenciou - e sofreu - no chamado front oriental, haja vista que, assim como a personagem, Hemingway também atuou como voluntário norte americano na Itália pela Cruz Vermelha, viveu os horrores da frente de batalha contra os austríacos, foi ferido gravemente na perna, o que o tirou do conflito, e ainda se apaixonou pela enfermeira inglesa que cuidou de seu ferimento, sem que fosse, no entanto, correspondido.

A forte presença da memória pode ser constatada no excerto em que Henry é ferido pelo obus de morteiro, uma das descrições mais chocantes e perturbadoras do livro, talvez revelando literariamente - ou tentando compartilhar com o leitor - a experiência impartilhável dos horrores da guerra. Assim o narrador nos descreve tal cena:

Ouvi de novo aquela tossida e depois o chuh-chuh-chuh-chuh - e depois um clarão de fornalha de alto-forno aberta, e um estrondo, e um branco que logo passou a vermelho e rolou como levado pelo vento. Procurei respirar, mas a respiração não me vinha e senti-me arrancado de mim mesmo e varrido por aquele vento. Saí completamente fora de mim e vi que estava morto, mas era um erro pensar que a gente morre. Depois flutuei, e em vez de sumir, senti que voltava a mim. Respirei e voltei a mim. O chão estava despedaçado e sobre a minha cabeça vi um grande estilhaço de vigota partida. Alguma coisa gritava sobre minha cabeça. Naquela tontura senti como se alguém estivesse chorando. Experimentei mover-me; não pude. Ouvi tiroteio de 
metralhadoras dos lados do rio. Grandes repuxos, e clarão de explosões, e clarão de foguetes, e estouro de granadas, tudo junto [...] Calor nas pernas, e umidade, e calor e umidade também dentro dos sapatos. Sabia que estava ferido e levei a mão ao joelho. Não achei o joelho: limpei minha mão na camisa, e à rápida claridade de um clarão lá fora pude ver minha perna e horrorizei-me. Ó Deus, Deus, tirai-me daqui (HEMINGWAY, 1979, p.52-53).

Ainda que seja uma citação extensa, ela se faz válida diante da voracidade e intensidade da descrição, que se torna ainda mais visceral pelo fato de ter sido composta em primeira pessoa, levando, indiretamente, o leitor a colocar-se no front junto com a personagem. Ou seja, de certa forma, o autor convida-nos a compartilhar com ele alguns aspectos - bastante traumáticos e violentos - da realidade da Primeira Guerra Mundial, dividindo conosco a sua traumática experiência do conflito, apresentando com palavras duras e fortes algumas de suas mais dolorosas características.

Podemos observar o nível do trauma provocado pela guerra na personagem através de uma passagem posterior da obra, em que ela, afastada do conflito após fracassar na missão que lhe havia sido atribuída durante uma retirada e desertar diante da captura e morte certa frente a soldados idealistas que ainda acreditavam na guerra como algo glorioso, evita qualquer contato com o conflito, mesmo que na forma de notícias nos jornais e busca, mesmo nas conversas cotidianas, escapar aos assuntos do front.

Eu havia comprado um jornal, mas não o li, porque não desejava saber nada da guerra. Queria esquecer a guerra. Eu havia feito paz em separado. Sentia-me horrivelmente só e respirei ao chegar a Stresa.

$[\ldots]$

O barman fez-me algumas perguntas.

- Não me fale na guerra, disse-lhe eu. A guerra está longe. Talvez nem haja mais guerra. Não há guerra aqui. 
Depois fiquei pensando que de fato a guerra acabara para mim. Me sentia como um garoto que fugiu da escola e ficava pensando no que estaria acontecendo por lá (HEMINGWAY, 1979, p.200-201).

Essa passagem específica - que se distribui em várias páginas do romance e mostra-nos o ânimo da personagem protagonista frente o conflito - é bastante reveladora no que concerne à exposição de suas memórias do conflito de forma individual: ao mesmo tempo em que há uma recusa em se lidar com uma memória traumática intensa, sua própria intensidade a torna indelével, conforme constatamos no emprego da metáfora do garoto que fugira da escola e pensava nos acontecimentos que nela se desenrolavam. Assim, o soldado pode ter saído da guerra e dela nada querer saber ou lembrar, mas jamais deixará de pensar - talvez mesmo de forma involuntária - sobre os acontecimentos que a rodeiam.

Um último elemento de grande interesse - e talvez o mais relevante para o presente artigo, por ser o ponto de conexão principal entre as obras de Hemingway e Remarque - é a crítica que se apresenta contra aqueles que defendiam a ocorrência da guerra como um evento glorioso na vida de um soldado, elevando a perigosos patamares conceitos de nacionalismo. Hemingway nos apresenta tal crítica em diferentes episódios de sua narrativa, porém selecionamos - por uma questão de limitação do presente estudo - apenas um deles, em que oficiais que jamais estiveram no campo de batalha adotam uma postura ufanista e violenta contra oficiais, soldados e civis em retirada do campo de batalha.

- Basta! É por causa de você, e outros como você, que os bárbaros pisam hoje no sagrado solo da pátria.

$[\ldots]$

- É por causa da traição de homens de sua laia que a Itália perdeu o fruto de tantas vitórias.

- Já esteve em alguma retirada? Perguntou o prisioneiro. 
- A Itália nunca se retira.

$[\ldots]$

Percebi como aqueles cérebros pensavam. Todos moços e salvando a pátria (HEMINGWAY, 1979, p.185).

O tom irônico com que a personagem - e através dela o próprio autor - revela sua opinião a respeito da atitude dos oficiais italianos, que jamais estiveram sob fogo, é bastante revelador do posicionamento e da crítica que faz Hemingway à glorificação da guerra e ao nacionalismo exacerbado, que sabemos, embora o fosse impossível para o autor em 1929, culminaria nos regimes totalitários de extrema direita apenas poucos anos depois.

No mesmo tom de crítica à ideia de glorificação da guerra e buscando mostrar os seus horrores de forma bastante clara e inegável, encontramos o romance de Erich Maria Remarche, pseudônimo de Erich Maria Kramer. O autor alemão, aos dezoito anos enviado para as trincheiras da Primeira Guerra Mundial, foi ferido três vezes, e de lá voltou com um intenso sentimento pacifista e anti-bélico, que o obrigou a refugiar-se nos Estados Unidos durante o governo de Hitler, onde escreveu diversos romances sobre os absurdos da guerra, sendo Nada de novo no front, de 1929, tal como o de Hemingway, o mais famoso deles.

A respeito dos horrores da guerra em si e da experiência traumática de participar de tão violento conflito, Remarque apresenta-nos detalhadas descrições em diversos momentos de sua obra, sendo a mais emblemática deles a que o autor faz de uma carga de ataque perpetrada pelos alemães contra uma trincheira aliada, com toda a decorrente carnificina, lembrando-nos muito a descrição de Hobsbawn anteriormente apresentada. Novamente, a narrativa em primeira pessoa contribui de forma bastante intensa para o 
clima de tensão do romance de Remarque, que parece também nos convidar a experienciar com ele o impartilhável.

Mas, poucos minutos depois, o ar enche-se de zunidos, a terra treme, soam gritos - uma granada acaba de pulverizar o último pelotão da retaguarda. Dispersamo-nos e atiramo-nos ao chão, mas, no mesmo instante, sinto que me abandona o sangue-frio que, sob o fogo, me leva inconscientemente a agir certo. Um pensamento me arrebata: "você está perdido", e um medo terrível parecer estrangular-me; no momento seguinte, sinto um impacto varrer como um chicote por sobre minha perna esquerda.

$[\ldots]$

Temos de passar por cima de uma cerca viva: é mais alta do que nós. Kropp agarra-se a um galho; seguro sua perna, e ele grita, dou-lhe um impulso, e ele pula para o outro lado. Com um salto, sigo atrás dele e caio numa vala que ficara oculta por trás da cerca.

Nossos rostos estão cobertos de lama, mas é um bom abrigo, então, afundamos na lama até o pescoço. Quando ouvimos o assobio de um projétil, mergulhamos as cabeças. [...] foi o medo que nos empurrou: mesmo se ambos os pés tivessem sido amputados, continuaríamos a correr sobre os cotos (REMARQUE, 1981, p.190-191).

Mais uma vez, podemos encontrar na narrativa literária a violência e a brutalidade da Primeira Guerra Mundial; desta vez por meio do ponto de vista do exército alemão, através da personagem protagonista Paul e de seus companheiros de armas, que vão tomando consciência da dura realidade do front de batalha e morrendo também, um após o outro, ao longo da narrativa, até que o próprio protagonista encontre seu fim em data que dista cerca de um mês da declaração do armistício e da assinatura do Tratado de Versalhes, que colocaria fim à guerra.

Um ponto bastante importante a respeito da realidade no front de batalha das trincheiras, que não aparece na obra de Hemingway, mas que é constante no texto de Remarque é a questão das condições de alimentação dos soldados que, quando não 
passavam fome literalmente, recebiam alimentação adulterada com produtos que visavam os manter alertas para a guerra, mas que não lhes davam o necessário sustento para a sobrevivência. Sobre esse aspecto destacamos o excerto seguinte:

Nossa comida é tão ruim e adulterada com tantos sucedâneos que ficamos doentes. Os donos de fábricas na Alemanha enriquecem, enquanto a disenteria nos corrói os intestinos. As latrinas estão sempre cheias de gente; deviam mostrar aos que ficaram em casa estes rostos terrosos, amarelos, miseráveis e resignados, estes vultos curvados, a quem a cólica esgota o sangue, e que, apesar disto, com os lábios trêmulos e contorcendo-se de dor, ainda conseguem rir com os outros e dizer:

- Nem vale a pena abotoar as calças (REMARQUE, 1981, p.220).

Além da questão da má alimentação e das doenças encontradas no front, o trecho destacado nos apresenta uma das pesadas críticas que o autor faz àqueles que provocaram a guerra e com ela lucraram e a ela glorificaram, ao referir-se aos "que ficaram em casa", e às coisas que o autor, através da fala da personagem, acredita que deveriam ser mostradas a tais pessoas.

O maior ponto de crítica à glorificação bélica, porém, aparece logo nas primeiras páginas do livro de Remarque e apresenta uma interpretação bastante aguda dos acontecimentos, bem como das suas trágicas consequências. Assim afirma-nos, de forma memorável, Remarque:

Kantorek nos leu tantos discursos nas aulas de ginástica que a nossa turma inteira se dirigiu, sob o seu comando, ao destacamento do bairro e alistou-se.

$[\ldots]$

É verdade que um de nós vacilou, e não quis acompanhar os demais. [...] Talvez houvesse outros que pensavam como ele, mas não ousaram proceder de outra forma, pois, naquela época, até os nossos próprios pais usavam facilmente a palavra "covarde". As pessoas não tinham nenhuma ideia do que estava por vir. Os mais sensatos eram realmente os 
pobres, os simples: viram logo que a guerra era uma desgraça, enquanto as classes mais altas não se continham de alegria, embora fossem elas justamente que deveriam ter previsto mais depressa as suas consequências (REMARQUE, 1981, p.15).

\section{(IN)CONCLUSÕES}

Por fim, tendo apresentado alguns conceitos de memória com os quais trabalhamos, e especialmente ao trazer duas obras literárias que discutem as questões da memória da Primeira Guerra Mundial, principalmente pelo fato de terem elas sido compostas através de memórias individuais de autores que participaram diretamente do conflito e apresentadas à memória coletiva como um grito contra a glorificação bélica, podemos concluir o presente artigo com a afirmação de que, tanto Hemingway como Remarque, em suas obras literárias, procuraram partilhar a impartilhável experiência da Primeira Guerra Mundial que carregavam em suas memórias.

Assim o fizeram não por que tais memórias fossem agradáveis, mas por que se fazia necessário mostrar ao mundo que um conflito militar da envergadura da Grande Guerra não é algo para ser romantizado ou esquecido, mas, sim, eternamente lembrado a fim de não ser repetido. Por meio de seus romances, Hemingway e Remarque corroboram a visão dos sobreviventes da Grande Guerra, apresentando-a não como espaço para a glória, mas como um local em que reinava - e predominava - o medo.

\section{REFERÊNCIAS}

AGAMBEN, Giorgio. Infância e História. Ensaio sobre a destruição da experiência. Belo Horizonte: UFMG, 2005.

BENJAMIN, Walter. Magia e técnica, arte e política. Ensaios sobre literatura e história da cultura. Obras escolhidas I. Tradução de Sérgio Paulo Rouanet. São Paulo: Brasiliense, 2016. 
GAGNEBIN, Jeanne Marie, Lembrar escrever esquecer. São Paulo: Editora 34, 2014.

HEMINGWAY, Ernest. Adeus às armas. Tradução de Monteiro Lobato. São Paulo: Companhia Editora Nacional, 1979.

HOBSBAWN, Eric. A era dos extremos. O breve século XX. 1914-1991. Tradução de Marcos Santarrita. São Paulo: Companhia das Letras, 1995.

REMARQUE, Erich Maria. Nada de novo no front. Tradução de Helen Rumjanek. Coleção Grandes Sucessos. São Paulo: Abril Cultural, 1981.

Artigo recebido em: 31 de maio de 2018. Artigo aprovado em: 06 de agosto de 2018. 